\section{Author's response: spontaneously breathing patients get tension pneumothorax}

In my brief letter ${ }^{1}$ I did not mean to imply that Leigh-Smith and Harris ${ }^{2}$ found the case reports they cited as unconvincing, merely that I did not find it convincing that supraatmospheric pleural pressure was the main explanation for the clinical condition of these patients. The ill patients in the cases cited by Leigh-Smith and Harris and reported by others ${ }^{3-10}$ all have either serious underlying lung disease, significant trauma or other problems. The index case they refer to, for example, had fallen three storeys down a lift shaft and in addition to a large pneumothorax had a ruptured spleen, left pulmonary contusion and lumbar and pelvic fractures. ${ }^{3}$ Patients with such multiple problems are likely to tolerate a large pneumothorax and consequent hypoxaemia badly and drainage of the pneumothorax is of course a vital part of their management.

I think that common usage and understanding takes 'tension' to imply that in tension pneumothorax the adverse physiological consequences are as a result of supra-atmospheric pressures. The BTS guidelines ${ }^{11}$ reflect this belief. The fact remains that intra-pleural pressure cannot exceed atmospheric pressure during inspiration and always does during expiration (or intercostal drainage of pneumothoraces would not work). There may be merit, as Leigh-Smith and Harris suggest, in retaining the expression tension pneumothorax to signify a large rapidly expanding pneumothorax causing severe physiological consequences but the risk is that retaining the word tension will perpetuate the misunderstanding that high pressures are the cause of this. We could of course retain the expression but use tension with one of its alternative meanings in that a tension pneumothorax would be one that can and should induce feelings of tenseness or anxiety in the medical attendants but this may not be a particularly productive way to approach medical terminology.

\section{Graham Simpson}

Correspondence to Dr Graham Simpson, Department of Thoracic Medicine, Cairns Base Hospital, PO Box 166, Stratford, Queensland 4870, Australia;

fgsimpson@iig.com.au

\section{Competing interests None.}

Provenance and peer review Commissioned; internally peer reviewed.

Accepted 23 November 2011

Published Online First 18 December 2011

Thorax 2012;67:356.

doi:10.1136/thoraxjnl-2011-201402

\section{REFERENCES}

1. Simpson G. Tension pneumothorax case report is misleading. Thorax 2012;67:355
2. Leigh-Smith S, Harris T. Tension pneumothorax - time for a re-think? Emerg Med J 2005;22:8-16.

3. Leigh-Smith S, Davies G. Tension pneumothorax: eyes may be more diagnostic then ears. Emerg Med 2003;20:495-6.

4. Holloway VJ, Harris JK. Spontaneous pneumothorax: is it under tension? J Accid Emerg Med 2000;17:222-3.

5. Jones R, Hollingsworth J. Tension pneumothoraces not responding to needle thoracocentesis. Emerg Med J 2002;19:176-7.

6. Wilkinson D, Moore $E$, Wither P, et al. ATLS on the ski-slopes-a steamboat experience. J Trauma 1992;32:448-51.

7. Vermeulen EG, Teng HT, Boxma H. Ventral tension pneumothorax. J Trauma 1997:43:975-6.

8. Barton ED. Tension pneumothorax. Curr Opin Pulm Med 1999:5:269-74.

9. Patterson BO, Itam S, Probst F. Spontaneous tension haemopneumothorax. Scand J Trauma Resusc Emerg Med 2008;16:12.

10. Morse JL, Safdar B. Acute tension pneumothorax and tension pneumoperitoneum in a patient with anorexia nervosa. J Emerg Med 2010;38:e13-16.

11. MacDuff A, Arnold A, Harvey J. Management of spontaneous pneumothorax: British Thoracic Society Pleural Disease Guideline 2010. Thorax 2010:65 (Suppl 2):ii18-32.

\section{Spontaneously breathing patients get tension pneumothoraces}

The recently published correspondence by Simpson is welcomed in so far as it correctly highlights some issues concerning tension pneumothorax. ${ }^{1}$ We agree that there are large differences in the pathophysiology and clinical manifestations of spontaneously breathing and mechanically ventilated patients presenting with a tension pneumothorax. It is also well established that hypoxaemia is a consistent finding in this disease and a hiss of air on pleural decompression can be misleading.

However, Simpsons's correspondence miscites the 2003 review by Leigh-Smith and Harris. ${ }^{2}$ First, we did not state that case reports of tension pneumothorax in spontaneously breathing patients were rare or unconvincing. In fact, we cited 18 case reports of spontaneously breathing patients with a convincing diagnosis of tension pneumothorax of both spontaneous and traumatic aetiology. ${ }^{2}$ Further, the index case which sparked the authors' interest in this subject was a very advanced tension pneumothorax in a spontaneously breathing patient. ${ }^{3}$ Since that case, over 10 years ago, we have seen (individually or by proxy through our interest in others' cases) multiple other examples of tension physiology in spontaneously breathing patients, unfortunately including a death due to non-treatment. Second, Simpson's referral to definitions of tension pneumothorax employing use of intra-pleural pressure (IPP) should refer to the original animal experiments, which pointed out that 'positive IPP throughout the respiratory cycle' was only a useful definition of tension pneumothorax in the ventilated subject. ${ }^{4} 5$ In awake subjects, the IPP must be less than atmospheric pressure during part of the respiratory cycle if air is going to continue to enter the pleural cavity. ${ }^{45}$
We believe that previous definitions of tension pneumothorax are of limited use because measurement of IPP is impractical, the extent of radiological mediastinal shift is variable $^{6}$ and hypotension occurs uncommonly in spontaneously breathing patients. ${ }^{2}$ We would therefore like to rehighlight a clinical definition for tension pneumothorax as being 'a pneumothorax that results in significant respiratory or haemodynamic compromise (the latter especially in ventilated patients) that reverses on thoracic decompression alone.'2

While acknowledging that ventilated patients usually present at the point of decompensation, in contrast to spontaneously breathing patients who normally present during a variable period of compensation, we believe that the term 'tension pnemothorax' should continue to be used for both conditions. The one word 'tension' immediately alerts the clinician to potential decompensation and the need for expedient investigation (ie, radiography or ultrasound) and/or thoracic decompression.

\section{Simon Leigh-Smith, ${ }^{1}$ Tim Harris, ${ }^{2}$ Derek J Roberts ${ }^{3}$}

${ }^{1}$ Emergency Department, Royal Infirmary of Edinburgh, Edinburgh, Scotland, UK; ${ }^{2}$ Departments of Emergency and Intensive Care Medicine and Pre-hospital Care, The Royal London and Newham University Hospitals, London, England, UK; ${ }^{3}$ Departments of Surgery, Community Health Sciences and Critical Care Medicine, University of Calgary, Foothills Medical Centre, Calgary, Alberta, Canada

Correspondence to Dr Simon Leigh-Smith, Emergency Department, Royal Infirmary of Edinburgh, 51 Little France Crescent, Old Dalkeith Road, Edinburgh EH16 4SA, UK; simon.leigh-smith@luht.scot.nhs.uk

\section{Competing interests None.}

Contributors SL-S and DJR drafted the first version of the manuscript. SL-S, TH and DJR provided critical revision of the manuscript for important intellectual content. All authors approved the final version of the manuscript prior to submission.

Provenance and peer review Not commissioned; internally peer reviewed.

Accepted 5 January 2012

Published Online First 27 January 2012

Thorax 2012:67:356.

doi:10.1136/thoraxjnl-2011-201307

\section{REFERENCES}

1. Simpson G. Tension pneumothorax case report is misleading. Thorax 2012;67:355.

2. Leigh-Smith $\mathbf{S}$, Harris T. Tension pneumothorax-time for a re-think? Emerg Med J 2005;22(Suppl 1):8-16.

3. Leigh-Smith $\mathbf{S}$, Davies $\mathrm{G}$. Tension pneumothorax: eyes may be more diagnostic than ears. Emerg Med $J$ 2003;20:495-6.

4. Rutherford RB, Hurt HH Jr, Brickman RD, et al. The pathophysiology of progressive, tension pneumothorax. J Trauma 1968;8:212-27.

5. Gustman P, Yerger L, Wanner A. Immediate cardiovascular effects of tension pneumothorax. Am Rev Respir Dis 1983;127(Suppl 2):171-4.

6. Clark S, Ragg M, Stella J. Is mediastinal shift on chest $\mathrm{X}$-ray of pneumothorax always an emergency? Emerg Med (Fremantle) 2003;15(Suppl 5-6):429-33. 